\title{
MARINE AEROSOL PROPERTIES AND THERMAL IMAGER PERFORMANCE (MAPTIP): SYNOPSIS
}

\author{
Gerrit de Leeuw and Alexander M.J. van Eijk \\ TNO Physics and Electronics Laboratory \\ P.O. Box 96864, 2509 JG The Hague, The Netherlands \\ phone +31 703740462, FAX +31 703280961 \\ email: deleeuw@fel.tno.nl, amjn1@fel.tno.nl \\ Douglas R. Jensen \\ Propagation Division \\ NCCOSC RDTE DIV D883 \\ 49170 Propagation Path \\ San Diego CA 92152-7385, USA \\ Phone: +1 619553 1415, FAX: +1 6195531417 \\ email: djensen@nosc.mil
}

\begin{abstract}
The MAPTIP (Marine Aerosol Properties and Thermal Imager Performance) experiment was organised as part of a project to assess atmospheric effects on the performance of electro-optical sensor systems in coastal areas. The main issue was the detection and identification of targets. The experiment took place at the North Sea from 11 October to 5 November, 1993, and was centred around Meetpost Noordwijk, a research tower $9 \mathrm{~km}$ from the Dutch coast. Platforms included a beach station, ship, research airplane, P3 Orion, helicopter and three buoys. The aim was to characterise the atmosphere (aerosols, extinction, turbulence, refractivity, and the vertical and horizontal variations of relevant meteorological parameters) in combination with detailed measurements of optical and $\mathbb{R}$ effects using thermal imagers, visual cameras, transmissometers and visibility meters, as well as a variety of point sources and ship, aircraft and helicopter serving as targets. Detection and identification ranges were determined and, for the interpretation of $\mathbb{R}$ signature measurements, $\mathbb{R}$ properties of extended targets were continuously monitored with radiometers. Extensive studies were made on polarisation effects, backgrounds and effects of sun glint. An overview of the experimental efforts and the ensuing analysis and modeling studies is presented. MAPTIP was the first validation of some recently developed atmospheric propagation models, including aerosol models, in a coastal environment. MAPTIP has yielded a wealth of data for the development of advanced aerosol models, description of horizontal variability, improvement of point target detection algorithms, validation of detection range models, and EOTDA validation.
\end{abstract}

\section{INTRODUCTION}

The development and assessment of the performance of electro-optical (EO) detection systems requires validated models describing the sensor and target characteristics, the background and the propagation medium. The propagation medium, i.e. the intervening atmosphere, introduces extinction, refraction and turbulence, leading to degradation of the radiance contrast between a target and its natural background, as viewed by the sensor. Atmospheric constituents absorb and scatter radiation. Therefore, atmospheric models used in the propagation prediction codes, in particular for aerosols but also for gaseous constituents, need to be accurate. Turbulence and refraction, due to temperature fluctuations and temperature gradients, respectively, cause blurring, scintillation, beam wander, mirages, etc. In thermal imagers, these effects may result in image distortion, contrast reduction and other detection problems. In this contribution we focus on atmospheric models and their validation.

Presently, the Atmospheric Transmission/Radiance computer code, LOWTRAN, ${ }^{44,45}$ or its more recent version MODTRAN, is the primary tool used for the assessment of atmospheric effects on systems performance. With the inclusion of the Navy Aerosol Model, NAM, ${ }^{46-53}$ into LOWTRAN6 and an upgraded version of NAM into 
LOWTRAN7, ${ }^{46}$ users are now able to determine the effects of aerosols on EO propagation in a maritime environment. This model has proven to be a useful tool in predicting transmission in the marine atmosphere along horizontal paths at shipboard levels (around $10 \mathrm{~m}$ ). In coastal areas the influence of continental aerosol renders the NAM predictions less reliable. The Navy Oceanic Vertical Aerosol Model (NOVAM) ${ }^{5464}$ has been developed to predict the vertical profiles of extinction, from shipboard heights upward, throughout the marine boundary layer and above, up to 5000 feet. NOVAM uses NAM as its kernel and the model accounts for the generation, dispersal and removal of the marine aerosols. However, to date, the NAM and NOVAM validation has been restricted to a limited range of meteorological situations and geographical locations and must be extended to include coastal regions which are often governed by substantial concentrations of continental aerosol. ${ }^{53}$ Also, recent studies have shown that NAM/NOVAM in their present forms should not be extrapolated into the region very near the surface of the ocean (below $10 \mathrm{~m}$ ) for predicting atmospheric properties. 53,65

The propagation properties in the lower few meters above the mean surface are important for the assessment of atmospheric effects on EO propagation over long ranges, along paths skimming the wave tops. Examples are Long-Range $\mathbb{R}$ Search and Track (LR-IRST) applications for detection of sea-skimming missiles, periscope detection, etc. The only available model for extinction near the ocean surface is an empirical formulation based on very few measurements over the open ocean ${ }^{58}$ In coastal areas this model has not been validated. However, based on comparisons of aerosol profile data, measured in different regions and under different meteorological conditions, ${ }^{53}$ this simple empirical formulation is not expected to be generally applicable.

Other effects that are important for long-range propagation close to the sea surface are turbulence and refraction. Turbulence increases significantly close to the surface, because of generation due to the friction between wind and waves. Refractivity is caused by refractive index structure due to temperature gradients. Turbulence and refraction are not taken into account in MODTRAN. Until recently these effects were not considered important over sea, because of low turbulence intensities and short propagation ranges. However, now that technological progress will allow for much longer detection ranges, the effects of turbulence and refraction may be significant factors. Models are being developed and validated based on experimental data. An example is IRTOOL, that includes extinction, turbulence, refraction, as well as other features required to assess $\mathbb{R}$ sensor performance. Models describing effects of refraction and turbulence are still being developed (e.g., refs. 30, 34, 35, 36) and experimental data are required for their validation.

It is therefore important to obtain more detailed information on atmospheric characteristics for the 3-5 and 8-12 $\mu \mathrm{m}$ wavelength bands in the first few meters above the sea surface, and to use this information in an effort to model this region (from the ocean surface to about $10 \mathrm{~m}$ ). Simultaneous characterisation of the atmosphere, and application of sensor systems for the detection of a variety of well-defined targets are required. In particular point targets within a few meters of the ocean surface are important, but also targets at higher elevations and extended targets.

\section{MAPTIP}

The MAPTIP (Marine Aerosol Properties and Thermal Imager Performance) experiment was the first effort to determine atmospheric effects on electro-optical propagation at low levels in coastal areas. The NATO AC/243 (Panel 4/RSG.8), a study group on atmospheric effects on EO propagation, planned and conducted MAPTIP with participation of NATO AC/243 (Panel 4/RSG.5) (IR targets and backgrounds). This cooperation brought together the unique combination of expertise required to obtain the necessary experimental data and for the subsequent interpretation.

MAPTIP thus had two main goals. The first was the development and validation of models describing atmospheric effects on electro-optical propagation properties (aerosol extinction, refraction and turbulence), in particular for (slant) long-range propagation paths. This required a comprehensive study of relevant atmospheric processes, both from the experimental and modeling points of view, at levels from the sea surface to the top of the boundary layer. Simultaneous application of IR-sensor systems was used to provide data for testing of the models in simulated operational conditions. The result, i.e. the validated models, are intended to be included in tactical decision aids for naval defence. 
The second aim of MAPTIP was the assessment of thermal imager performance in a maritime environment. This requires, apart from atmospheric effects, ship signatures and other target characteristics, models for backgrounds and clutter, etc., in a variety of atmospheric conditions. This topic will not be discussed in this contribution. More information and references can be found in ref. 26.

The MAPTIP experiment was conducted in the North Sea, October 11 - November 5, 1993. The focal point was Meetpost Noordwijk (MPN), position $45^{\circ} 16^{\prime} 25.9^{\prime \prime} \mathrm{N} ; 04^{\circ} 17^{\prime} 45.8^{\prime \prime}$ E. MPN is a research tower $9 \mathrm{~km}$ from the Dutch coast, owned and maintained by the Dutch Ministry of Public Works. This coastal location is subjected to strong anthropogenic influences. Surrounding land masses of continental Europe and the UK include industrial areas, large cities and agricultural and nural areas. North-westerly wind directions, however, bring clean polar air masses that are representative of open-ocean conditions, ${ }^{57}$ in combination with large fetches. In addition to MPN, MAPTIP platforms included a beach station in Katwijk, a ship, the NRaD airborne platform, the oceanographic research vessel Hr.Ms.Tydeman, a P3 Orion, a Lynx helicopter and three buoys.

Aerosol and meteorological instnuments, thermal imagers and calibrated targets, were utilised on the MAPTIP platforms, cf. refs. 4, 6, or 12 for extensive descriptions of the MAPTIP experiment. This network of instrumentation was used for obtaining a comprehensive data base of aerosol size distributions, including surface layer profiles of the aerosol and (size segregated) chemical composition and relevant meteorological variables. Profiles of aerosol particle size distributions and meteorological parameters in the marine atmospheric boundary layer were measured with radiosondes and with the $\mathrm{NRaD}$ airborne platform.

Information was also required for the development of the next generation aerosol model ANAM (Advanced Navy Aerosol Model). Emphasis was placed on observations close to the ocean surface (below $10 \mathrm{~m}$ ). Thermal imagery was also included to provide ground truth for assessing the ANAM model development for low-level propagation. For characterisation of spatial variation effects on electro-optical propagation in this coastal area, measurements on the horizontal distribution of the aerosol and the meteorological variables were made using the Hr. MS. Tydeman and the $\mathrm{NRaD}$ airborne platform.

Further, measurements of atmospheric turbulence and refractivity effects in the visible and $\mathbb{I R}$ bands were made to assess marine boundary layer effects on the degradation of thermal images that were recorded from the various platforms.

MAPTIP was organised by the TNO Physics and Electronics Laboratory (The Hague, The Netherlands), and supervised by a scientific committee chaired by Dr. Jensen from NCCOSC, with participation of about 50 scientific and engineering personnel from 16 scientific institutes located in 9 countries. ${ }^{1}$

\section{THE MAPTIP DATA}

A large data set was collected during MAPTIP, including thermal images, video recordings of refractive effects, 3$D$ lidar maps showing boundary layer dynamical behaviour, etc. Support data include the meteorological data, aerosol data and the calculated extinction coefficients that are needed for the analysis and interpretation of the results.

Aerosols and meteorological parameters were measured by different groups, on different platforms, and with different instrumentation. For instance, some of the meteorological parameters were measured during MAPTIP by as many as nine different instruments. For an unambiguous interpretation of the MAPTIP results, it is of crucial importance that the support data are reliable and single-valued. Therefore, a strong effort has been made to deliver consensus data sets both for the meteorological parameters ${ }^{21}$ and for the aerosol size distributions, cq. extinction coefficients. ${ }^{23}$ See ref. 26 for a brief summary. 


\subsection{Development and validation of aerosol models}

One of the principal objectives of MAPTIP was to collect data for the development of a model that describes the aerosol concentrations in the lowest few meters above the sea surface (ANAM). To accomplish this, NRaD deployed an instrument package with optical particle counters, rotorods and meteorological equipment ${ }^{14,27}$ that was lowered from MPN to just above the wave tops. Data were collected at a range of levels, thus providing aerosol and meteorological 'profiles'. Due to the wind direction relative to MPN, that was generally encountered during MAPTIP but is not common for the area in the fall, few data were collected for which the samplers had optimum exposure to air masses advected from open sea. Nevertheless, enough data were collected to allow for the determination of the variation of the extinction values with height. The analysis of the aerosol size distributions led to the formulation of a preliminary version of ANAM $^{27}$ The large-particle mode that had earlier been suggested ${ }^{60}$ (NAM mode 4) is presented as a log-normal distribution with a mode radius that is independent of wind speed, and a mode amplitude that increases exponentially with wind speed. ${ }^{27}$ At wind speeds above $5-6 \mathrm{~m} / \mathrm{s}$ the evidence of a gradient in the concentrations of large aerosols disappears. The turbulence produced by the high wind speed also mixes the large aerosol in the lowest $10 \mathrm{~m}$ of the atmosphere. As a result, any vertical structure in the aerosol spectrum disappears while the net amount of large aerosol increases non-linearly with the wind speed.

The analysis ${ }^{19}$ of the rotorod data measured by TNO from the north side of the platform, using a mast extending $10 \mathrm{~m}$ out (cf. ref. 73 for a description), shows that the gradients can be described by existing surface layer formulations. However, in many other cases, positive gradients were observed, a situation that cannot be handled by the model. Physically, positive gradients, i.e. concentrations at elevated levels that are larger than close the source, are not likely. However, in off-shore winds, particles advected form land need to be considered as well as the balance between these continental particles and freshly produced aerosol. The situation is complicated by the relatively short fetches, developing wave fields and developing boundary layers, all resulting in different transport regimes. This is a very complicated situation that cannot be described by current aerosol transport models.

Existing empirical aerosol models are not always reliable in coastal areas. An evaluation of NAM with the HEXOS aerosol data collected at MPN in 1986 has clearly indicated the large discrepancies in continentally influenced air masses. ${ }^{53}$ In purely marine air masses, on the other hand, NAM predictions for the MPN area compare favourably with experimental data. The HEXOS aerosol data set has been analysed to identify the most important parameters affecting the aerosol concentrations, and an empirical model has been formulated. ${ }^{7}$ This HEXOS model has been validated with the MAPTIP data collected at the MPN. ${ }^{13}$ The model has been extended for wind directions that were not available in the HEXOS data set. ${ }^{67,13}$ During MAPTIP the wind was mainly from easterly directions, as opposed to the westerly winds that usually prevail in the fall in this area.

Using the aerosol particle size distributions measured during MAPTIP on Hr.Ms. Tydeman, the HEXOS model was evaluated for North Sea areas other than MPN. The analysis clearly shows that the model performance degrades rapidly with the distance to the area for which it was developed. ${ }^{13}$

The spatial variability was investigated using the MPN/Tydeman aerosol and meteorological data sets. ${ }^{28}$ Horizontal variations of both the aerosol and the meteorological parameters were clearly demonstrated. Concentrations of large aerosol particles (typically $5 \mu \mathrm{m}$ ) increased with fetch. On the other hand, the expected decrease in the concentrations of the small aerosol particles $(0.5 \mu \mathrm{m}$ as a typical example) was not significant. The time lags between variations occurring at MPN, and downwind from MPN at the Tydeman, are in good agreement with the time required to transport the air mass.

Further evidence for the horizontal variation of the aerosol concentrations was provided by the aerosol maps produced from the data collected with the $\mathrm{NRaD}$ airborne platform. In contrast to the analysis of the data from Hr.Ms. Tydeman, the aircraft data did indicate considerable structure in the smallest sizes. Strong gradients were observed and plumes were clearly identified. ${ }^{15}$ The aircraft measured in a relatively small area (on the order of 25 $\mathrm{km}$ ) during a short time in which aerosol plumes may have had little time to disperse. The aircraft data therefore 
may be representative of local plumes. The ship, on the other hand, measured over larger distances ( $200 \mathrm{~km})$ during long times and used the MPN data as reference.

In analogy with the above discussion on the vertical gradients, a detailed description of the horizontal variations is complicated by the vicinity of land-based sources and the fetch-dependent generation of fresh marine aerosol. The wave field is not fully developed at short fetches. A small-scale coastal aerosol model is needed to adequately take into account complex structures of the coastal environment. An effort to get better insight into coastal phenomena is underway in the framework of EOPACE (Electro-Optical Propagation Assessment in Coastal Environments). ${ }^{71}$

Chemical analyses of the aerosol composition were made using data collected on MPN and Hr. Ms. Tydeman. The MPN data include volatility samples that give insight in the composition of the aerosol. ${ }^{16}$ The ship data were impactor samples that were analysed on the elemental composition of the size fractionated aerosol. Results were used in the studies on the horizontal variability of the aerosol ${ }^{13}$ and gave a clear indication of the influence of anthropogenic aerosol. These results were further used in a study on aerosol deposition into the North Sea. ${ }^{42}$

\subsection{Extinction}

Direct measurements of extinction coefficients were made with visibility meters operated by DREV. ${ }^{37}$ These data were used in the formulation of the consensus aerosol data set as discussed in section 2.

In addition, extinction coefficients were determined from the variation of the intensity of the source suspended under the Lynx helicopter, as observed with thermal imagers at MPN, when the helicopter moved away from the tower. These data compare favourably with extinction coefficients derived from the measured aerosol particie size distributions and MODTRAN calculated molecular extinction. When, instead of the 'experimental' aerosol extinction, extinction values were used that were calculated with MODTRAN, using either the maritime model or the urban model, large discrepancies were observed. This result indicates that the use of existing models in this coastal environment may lead to wrong conclusions. The effect of continental aerosol must be taken into account, but it is not clear, a priori, how this must be done. Obviously, this requires the application of an aerosol transport model with the appropriate length scales.

Extinction coefficients at a wavelength of $1.064 \mu \mathrm{m}$ were deduced from measurements with the IFU lidar. ${ }^{29}$ Over the surf zone the extinctions are clearly enhanced and are in the range $0.05-0.3 \mathrm{~km}^{-1}$. These values are in agreement with low-level extinction values calculated from the aerosol measured from MPN. ${ }^{28}$ Since IFU lidars were used at four wavelengths, the wavelength dependence of the extinction coefficients could be determined. ${ }^{29}$

\subsection{Marine boundary layer and surf zone characterisation by lidar and horizontal variability}

Lidar provides a unique remote sensing tool for the characterisation of atmospheric properties such as boundary layer structures, turbulence, convective cells and the variation of extinction in both the horizontal and the vertical dimension. During MAPTIP, lidars were used at MPN and at the beach station., 29 Convective and turbulent mixing were clearly demonstrated, in many occasions, with the TNO lidar on MPN. The influence of waves on the surface layer structures (below $10 \mathrm{~m}$ ) were revealed and ship plumes could be detected. The IFU lidar at the beach station clearly demonstrated larger scale structures at somewhat higher elevations, with periods of $300-400 \mathrm{~m}$. The effect of the surf on the extinction was also clearly visible.

MAPTIP was one of the first experiments where the IFU eye-safe lidar was used (after VAST92, another NATO $\mathrm{AC} / 243$ (Panel 4/RSG.8) trial). ${ }^{8}$ The extinction in fog is much lower at the eye-safe wavelength (1.56 $\left.\mu \mathrm{m}\right)$ then at the wavelength of $0.532 \mu \mathrm{m}$ (factor 7). See also section 3.2 for extinctions measured with the lidar.

\subsection{Refraction}

Refractivity effects during MAPTIP were studied by three groups. ${ }^{18,}, 30,40$ MAPTIP was the first validation of the French model PIRAM. ${ }^{22}$ For the WKD model from DREV it was the second test at open sea. The results are in satisfactory agreement with model predictions in both the mid-infrared and the visible. Differences are ascribed to 
inhomogeneities in the MBL due to coastal influences. ${ }^{18} \mathrm{~A}$ comparison between the PIRAM and WKD models is presented in ref. 30. The Maximum Inter-Visibility Range (MIVR) was often well within $1 \mathrm{~km}$ of the measured values, and always within $2 \mathrm{~km}$. The minimum mirage range and maximum and minimum mirage height predictions are also reasonably good.

\subsection{Effects of turbulence on long-range measurements}

Several models describing effects of turbulence on EO propagation are available in the MAPTIP community. Direct measurements were made for the evaluation of these models, ${ }^{35}$ and for comparison with bulk formulations. ${ }^{19,34}$ The bulk turbulence model was compared with direct measurements of the friction velocity $u$. from the NPS buoy to test its predictive value. ${ }^{19}$ This is extremely valuable for those occasions when direct measurements are not available. The comparison led to the conclusion that the bulk values are sufficient for characterisation when no data are available. The inertial-dissipation derived $u$. is larger than the bulk derived values, probably due to the bulk formulation at short fetches. Values for the temperature structure function parameter $\mathrm{C}_{\mathrm{T}}{ }^{2}$ were derived from the bulk formulation and from the inertial dissipation method. The results are in good agreement for $\mathrm{C}_{\mathrm{T}}{ }^{2}>10^{-2}$, i.e. in strongly unstable conditions. ${ }^{34}$ In the lower $\mathrm{C}_{\mathrm{T}}{ }^{2}$ regime the turbulent fluctuations of temperature are not important for optical propagation.

The TNO-FEL bulk meteorological model has been validated with measurements of optical turbulence. ${ }^{35}$ This was done in an extension of the MAPTIP work. The measurements were made along a $19 \mathrm{~km}$ propagation path that was completely over water. The model predicts the scintillation and refractive index structure function parameter $\left(\mathrm{C}_{\mathrm{N}}{ }^{2}\right)$ well in on-shore winds. In off-shore winds, a non-equilibrium situation is created in which the theory does not strictly apply. The comparison between the model predictions and the experimental data confirms that large discrepancies may occur.

\section{CONCLUSION}

An overview has been presented of the accomplishments and achievements from the MAPTIP experiment in the field of modeling and model validation. Other important topics are detection ranges, polarisation, ship signatures and background and clutter models. Details have been presented in, thus far, 40 publications. ${ }^{1-40}$ The MAPTIP data are also being used for other studies. ${ }^{41-43}$ MAPTIP has served as a testbed for the first validation of atmospheric propagation models, ${ }^{18,36,40,72}$ and aerosol models. ${ }^{13,19,28}$ This has resulted in the preliminary formulation of ANAM. ${ }^{27}$ Surf zone effects were reported. ${ }^{29}$ Horizontal variability of aerosol concentrations, and thus aerosol extinction, was indicated on various scales, ranging from hundreds of meters $\mathrm{s}^{29}$ to some tens of $\mathrm{km}^{15}$ and also to hundreds of $\mathrm{km}^{28}$ Turbulence models were tested with regard to their predictive value. ${ }^{34}$ Detection range models and EOTDA were validated ${ }^{9,32}$ and the application of polarisation filters has resulted in a wealth of knowledge that can be used, e.g., to improve the contrast between target and background. Point target detection algorithms were significantly improved. ${ }^{17,31,39}$ The use of lidar to reveal structures in the marine boundary layer, as well as in the surface layer, has been demonstrated. ${ }^{29}$ Extinction coefficients were measured with lidar ${ }^{29}$ and with visibility meters $^{37}$ for model validation. The results also demonstrate the use of lidar as a tool for remote sensing of the propagation environment. An assessment has been made on the use of MODTRAN in coastal regimes. ${ }^{31}$

Studies on electro-optical propagation effects in the coastal environments are continued in EOPACE. ${ }^{71}$ EOPACE experiments are taking place in Southern California, centred around San Diego and Monterey, during 1996-1997. Among the objectives of EOPACE are:

- characterise aerosol production in the surf zone and its effects on transmission in the visible and IR wavelengths, - characterise the air mass in an off-shore flow and the inherent changes in aerosol content and optical properties, - long-range transmission $(7,15,22 \mathrm{~km})$ and scintillation measurements.

The wide variety of instrumentation used in the EOPACE experiments includes aerosol counters, meteorological instruments, radiometers, lidar, satellite remote sensing, polarisation measurements, thermal imaging and IRST performance. EOPACE intensive observational periods (IOPs) took place in April and November 1996, both centered around San Diego Bay. During the April IOP, an air mass characterisation experiment was also conducted in the Los Angeles basin. The aerosol plume was sampled from a ship providing ground truth aerosol particle size 
distributions and chemical composition, meteorological data, and radiosonde and lidar profiles, while aerosol optical depth was retrieved from satellite data (AVHRR). The first surf zone experiments were conducted in San Diego, off Scripps Pier, in January/February 1996, and in Monterey Bay off the Moss Landing Marine Institutes Pier in March 1996. Long-range transmission was measured across Monterey Bay over a $22 \mathrm{~km}$ path.

MAPTIP was supported by NATO AC/243 (Panel 4) (Grants 6056 and 6092) and by the US Office of Naval Research ONR (Grant N00014-91-J-1948). The remaining logistics costs were shared by the individual participants listed in Table 2. The Netherlands Royal Navy made available the oceanic research vessel Hr.Ms. Tydeman, a Lynx helicopter, a P3 Orion and the Naval Air Station Valkenburg, and provided logistics support for these platforms. The efforts of the crews and personnel of these platforms made MAPTIP a success. The activities of the TNO Physics and Electronics Laboratory were supported by the Netherlands Ministry of Defence (assignments A91KM614, A91KM615 and A92KM776). The NCCOSC participation was funded under program element 62435N, RL3C Project RO35E82/01, Marine EO Effects. We wish to express our thanks to Direktie Noordzee of the Dutch Ministry of Public Works for the cooperation, advice and the use of MPN, the Scheveningen harbour facility, the ships Albatros and Smal Agt, and the dedication of the respective crews, in particular the crew of MPN. KNMI made available the boom at MPN. The MAPTIP experiment was organised by the TNO Physics and Electronics Laboratory. We thank our colleagues at TNO-FEL for their dedication. The authors also wish to acknowledge the fine cooperation with other colleagues in the MAPTIP project. The present compilation of results is only a small sample, reflecting the huge amount of work that has been done in MAPTIP.

1. Jensen, D.R., G. de Leeuw and A.M.J. van Eijk (1993). Work plan for the Marine Aerosol Properties and Thermal Imager Performance trial (MAPTIP). Naval Command, Control and Ocean Surveillance Center, San Diego, CA, USA, Technical Document 2573 (September 1993).

2. Taczak, W., (Ed.) (1993). MAPTIP quick-look report. Prepared by Office of Naval Research, Arlington, VA, USA.

3. Chan, Padres M. (1993). Experimental Investigation of Infrared Polarization Effects in Target and Background Discrimination, MS Thesis, NPS, December 1993.

4. De Leeuw, G., A.M.J. van Eijk and D.R. Jensen (1994). MAPTIP experiment, Marine Aerosol Properties and Thernal Imager Performance: An overview. TNO Physics and Electronics Laboratory, report FEL-94-A140.

5. Jensen, D.R., G. de Leeuw and A.M.J. van Eijk (1994). Summary of the Marine Aerosol Properties and Thermal Imager Performance Trial (MAPTIP). Presented at the meeting of the International Union of Radio Science (URSI), 6-8 January 1994, Univ. Colorado, Boulder (CO), USA.

6. Van Eijk, A.M.J., D.R. Jensen and G. de Leeuw (1994). MAPTIP experiment, Marine Aerosol Properties and Thermal Imager Performance. In Atmospheric Propagation and Remote Sensing III, W.A. Flood and W.B. Miller (Eds.), SPIE Proceedings 2222, 299-315.

7. Cooper, A.W., W.J. Lentz, P.I. Walker and P.M. Chan (1994). Infrared Polarization Measurements of Ship Signatures and Background Contrast, In Characterization and Propagation of Sources and Backgrounds, Wendell W. Watkins and Dieter Clement, Eds, Proceedings SPIE Vol. 2223, pp. 300 - 309.

8. Carnuth, W. and T. Trickl (1994). A powerful eyesafe aerosol lidar: application of stimulated Raman backscattering of $1.06 \mu \mathrm{m}$ radiation. Rev. Sci. Instrum.. 65, 3324-3331.

9. De Jong, A.N. (1994). NL ship-IR imagery at MAPTIP, TNO Physics and Electronics Laboratory, Report FEL94-A143.

10. Moretz, D.G. (1994). Analysis of Target Contrast Improvement using Polarization Filtering in the Infrared Region; MS Thesis, Naval Postgraduate School, December 1994.

11. Walker, P.L., W.J. Lentz, and A.W. Cooper "Atmospheric and Sea State Dependence of Polarized Infrared Contrast", SPIE Proceedings Vol 2469, 393-399, (1995).

12. Jensen, D.R, G. de Leeuw and A.M.J. van Eijk (1995). Summary of the Marine Properties and Thermal Imager Performance Trial (MAPTIP). AGARD electromagnetic wave propagation panel 55th specialists' meeting on 
"Propagation assessment in coastal environments", Bremerhaven, Germany, 19-23 September, 1994. AGARD CP 567, pp. 18-1 to 18-10.

13. Van Eijk, A.MJ., F.H. Bastin, F.P. Neele, G. de Leeuw and J. Injuk (1995). Characterisation of atmospheric properties during MAPTIP. AGARD electromagnetic wave propagation panel 55th specialists' meeting on "Propagation assessment in coastal environments", Bremerhaven, Germany, 19-23 September, 1994. AGARD CP 567, pp. 19-1 to 19-8.

14. Gathman, S.G. (1995). Aerosol profiles near the sea surface during MAPTIP. AGARD electromagnetic wave propagation panel 55th specialists' meeting on "Propagation assessment in coastal environments", Bremerhaven, Germany, 19-23 September, 1994. AGARD CP 567,pp. 20-1 to 20-11.

15. Gathman, S.G. and D.R. Jensen (1995). Aerosol maps made during MAPTIP. AGARD electromagnetic wave propagation panel 55th specialists' meeting on "Propagation assessment in coastal environments", Bremerhaven, Germany, 19-23 September, 1994. AGARD CP 567, pp. 21-1 to 21-7.

16. Smith, M.H. (1995). UMIST observations of accumulation mode aerosol concentrations and composition during MAPTIP. AGARD electromagnetic wave propagation panel 55th specialists' meeting on "Propagation assessment in coastal environments", Bremerhaven, Germany, 19-23 September, 1994. AGARD CP 567, pp. 22-1 to 22-8.

17. Stein, K, A. Kohnle, W. Schuberth and R Jantzen (1996). Impact of coastal environment on point target detection. AGARD electromagnetic wave propagation panel 55th specialists' meeting on "Propagation assessment in coastal environments", Bremerhaven, Germany, 19-23 September, 1994. AGARD CP 567, pp. 23-1 to 23-10.

18. Forand, J.L., D. Dion and J. Beaulieu (1995). MAPTIP: Canada's measurements of refraction effects. AGARD electromagnetic wave propagation panel 55th specialists' meeting on "Propagation assessment in coastal environments", Bremerhaven, Germany, 19-23 September, 1994. AGARD CP 567, pp. 24-1 to 24-7.

19.Davidson, K.L., P.A. Frederickson and G. de Leeuw (1995). Surface layer turbulence and aerosol profiles during MAPTIP. AGARD electromagnetic wave propagation panel 55th specialists' meeting on "Propagation assessment in coastal environments", Bremerhaven, Germany, 19-23 September, 1994. AGARD CP 567, pp. 25-1 to 25-9.

20. Cooper, A.W., W.J. Lentz, P.L. Walker and P.M. Chan (1995). Polarization enhancement of contrast in infrared ship/background imaging. AGARD electromagnetic wave propagation panel 55th specialists' meeting on "Propagation assessment in coastal environments", Bremerhaven, Germany, 19-23 September, 1994. AGARD CP 567, pp. 26-1 to 26-10.

21.De Leeuw, G., A.M.J. van Eijk and D.R. Jensen (1996). MAPTIP Analysis Workshop, Quebec, May 24-25, 1995. In preparation.

22. De Leeuw, G., A.MJ. van Eijk and D.R. Jensen (1995). MAPTIP - Marine aerosol properties and thermal imager performance: summary and initial results. In 9th Meeting on Optical Engineering in Israel, I. Shladov, Y. Weissman, N. Kopeika (Eds.), SPIE Proceedings 2426, 67-78.

23. Smith, M.H. (1995). Aerosol measurements on the MPN during MAPTIP: is there an aerosol consensus? Report, University of Manchester Institute of Science and Technology, Manchester, UK.

24. De Jong, A.N. (1996). Proceedings NATO IRIS meeting, London, UK, 25-28 June, 1996.

25. Dainty, J.C., and L.R. Bissonnette, Editors (1996). Image Propagation Through the Atmosphere, Proc. SPIE 2828.

26. De Leeuw, G., A.M.J. van Eijk and D.R. Jensen (1996). Marine Aerosol Properties and Thermal Imager Performance (MAPTIP): an overview. In: Image Propagation Through the Atmosphere, J.C. Dainty and L.R. Bissonnette, Editors, Proc. SPIE 2828, 2-14.

27. Gathman, S.G. (1996). MAPTIP observations of large aerosol in the lowest $10 \mathrm{~m}$ above waves. In: Image Propagation Through the Atmosphere, J.C. Dainty and L.R. Bissonnette, Editors, Proc. SPIE 2828, 15-23.

28. Van Eijk, A.MJ., G. de Leeuw and M.M. Moerman (1996). Lateral variations of meteorological properties and aerosols in off-shore winds. In: Image Propagation Through the Atmosphere, J.C. Dainty and L.R. Bissonnette, Editors, Proc. SPIE 2828, 24-30.

29. Kunz, G.J. and T. Trickl (1996). Lidar measurements of atmospheric extinction during the MAPTIP trial. In: Image Propagation Through the Atmosphere, J.C. Dainty and L.R. Bissonnette, Editors, Proc. SPIE 2828, 3138.

30. Forand, J.L. (1996). MAPTIP: refractive effects in the visible and IR In: Image Propagation Through the Atmosphere, J.C. Dainty and L.R. Bissonnette, Editors, Proc. SPIE 2828, 39-49. 
31. Schwering, P.B.W., G. de Leeuw and A.M.J. van Eijk (1996). Transmission of 10 micron radiation over coastal waters: comparison of point source image intensities with aerosol extinction and MODTRAN calculations. In: Image Propagation Through the Atmosphere, J.C. Dainty and L.R. Bissonnette, Editors, Proc. SPIE 2828, 6475.

32. McGrath, C.P., P.B.W. Schwering and P.J. Fritz (1996). A comparison of MAPTIP FLIR detection ranges to the EOTDA prediction model. In: Image Propagation Through the Atmosphere, J.C. Dainty and L.R. Bissonnette, Editors, Proc. SPIE 2828, 76-84.

33. Cooper, A.W., W.J. Lentz and P.L. Walker (1996). Infrared polarization ship images and contrast in the MAPTIP experiment. In: Image Propagation Through the Atmosphere, J.C. Dainty and L.R Bissonnette, Editors, Proc. SPIE 2828, 85-96.

34. Davidson, KL., and P.A. Frederickson (1996). Small-scale turbulence measurements from a buoy during MAPTIP. In: Image Propagation Through the Atmosphere, J.C. Dainty and L.R Bissonnette, Editors, Proc. SPIE 2828, 97-107.

35. Kunz, G.J., M.M. Moerman, P.J. Fritz and G. de Leeuw (1996). Validation of a bulk turbulence model with thermal images of a point source. In: Image Propagation Through the Atmosphere, J.C. Dainty and L.R. Bissonnette, Editors, Proc. SPIE 2828, 108-116.

36. Forand, J.L., and D. Dion (1996). Predictive comparisons of marine boundary layer models. In: Image Propagation Through the Atmosphere, J.C. Dainty and L.R. Bissonnette, Editors, Proc. SPIE 2828, 129-140.

37. Hutt, D. L. (1996). Estimate of effective aerosol droplet radius from visible and infrared extinction measurements. In: Image Propagation Through the Atmosphere, J.C. Dainty and L.R. Bissonnette, Editors, Proc. SPIE 2828, 503-514.

38. De Leeuw, G., A.M.J. van Eijk and M.M. Moerman (1996). Aerosol dynamics over the North Sea in off-shore winds. J. Aerosol Sci. 27, Suppl. 1, S63-S64.

39. Schwering, P.B.W., and H.A. Lensen (1996). Infrared point source behaviour during the MAPTIP trials. TNO Physics and Electronics Laboratory, Report FEL-94-A326.

40. Forand, J.L., Y. Hurtaud and K. Stein (1996). MAPTIP work group report: Refractive effects in the visible and the Infrared. Defence Research Establishment Valcartier, Quebec, Canada, Report DREV-MM-NNNN (in preparation).

41. Piazzola, J. (1996). Etude de la repartition verticale des particules d'aerosols an voisinage de l'interface mer-air en zone cotiere Mediterraneene. PhD Thesis, L'Universite de Toulon et du Var.

42. Injuk, J., R van Grieken and G. de Leeuw (1996). Deposition of atmospheric trace elements into the North Sea: coastal, ship, platform measurements and model predictions. Submitted for publication in Atm. Env. (June 1996).

43. Flossmann, A.I, W. Wobrock, P.J.H. Builtjes, M. Roemer, G. de Leeuw, A.M.J. van Eijk, P.G. Mestayer, B. Tranchant, S.E. Larsen, L.-L.S. Geernaert, E. Ljungstrom and R. Karlson (1996). Vertical fluxes in the marine boundary layer. In preparation.

44. Kneizys, F.X., E.P. Shettle, W.O. Gallery, J.H. Chetwynd, Jr., J.H Abreu, J.E.A. Selby, S.A. Clough and R.W. Fenn (1983). Atmospheric Transmittance/Radiance: Computer Code LOWTRAN 6, Air Force Geophysical Laboratory Technical Report No. 83-0187, August 1983.

45. Kneizys, F.X., E.P. Shettle, L.W. Abreu, J.H. Chetwynd, G.P. Anderson, W.O. Gallery, J.E.A. Selby, and S.A. Clough (1988). Users Guide to LOWTRAN 7, Air Force Geophysical Laboratory Technical Report No. 880177 , Aug 1988.

46. Gathman, S.G. (1983a). Optical Properties of the Marine Aerosol as Predicted by the Navy Aerosol Model, Opt. Eng. 22, 57-62.

47. Gathman, S.G. (1983b). Optical Properties of the Marine Aerosol as Predicted by a BASIC Version of the Navy Aerosol Model, NRL Memo Report \#5157.

48. Gathman, S.G. (1984). Navy Hygroscopic Aerosol Model. In: Hygroscopic Aerosol, L.H. Ruhnke \& A. Deepak, editors, A. Deepak publisher, Hampton, VA., p93.

49. Hughes, H.G. (1987). Evaluation of the LOWTRAN 6 Navy Maritime Aerosol Model Using 8 to 12 micron Sky Radiances. Opt. Eng., Vol. 26, \#11, 1155-1160.

50. Battalino, T.E., and R.A. Helvey (1985). Air Mass Parameterization in the Navy Aerosol Model. Geophysical Sciences Technical Note \# 103, PMTC, Point Mugu, CA.

51. Gerber, HE. (1985). Relative-Humidity Parameterization of the Navy Aerosol Model (NAM). NRL Report \#8956, December 1985. 
52. Hughes, H.G., and M.R. Paulson (1989). Lidar Technique for Adjusting Aerosol Model Number Densities to Existing Conditions. NOSC TD \#1637, September 1989.

53. De Leeuw, G. (1993a). Aerosol effects on electro-optical propagation over sea. In: 8th meeting on Optical Engineering in Israel: Optical Engineering and Remote Sensing, M. Oron, I. Shladov and Y. Weissman (Eds.) Proc. SPIE 1971, 2-15.

54. Gathman, S.G. (1989). A Preliminary Description of NOVAM, the Navy Oceanic Vertical Aerosol Model. NRL Report \#9200.

55. Gathman, S.G. (1992). Ocean Aerosol Measurements and Models in the Straits of Florida (The Key-90 Experiment). Atmospheric Propagation and Remote Sensing, A. Kohnle and W.B. Miller, editors, SPIE proceedings Vol. 1688, 2-13.

56. Gathman, S.G., G. de Leeuw, K.L. Davidson and D.R. Jensen (1989). The Navy Oceanic Vertical Aerosol Model: Progress Report. In: Atmospheric propagation in the UV, visible, $\mathbb{R}$ and $\mathrm{mm}$-wave region and related systems aspects, AGARD-CP-454 17-1 to 17-11.

57. Gathman, S.G., S.G., D.R. Jensen, W.P. Hooper, J.E. James, H.E. Gerber, K.L. Davidson, M.H. Smith, I.E. Consterdine, G. de Leeuw, G.J. Kunz and M.M. Moerman (1993). NOVAM evaluation utilizing electro-optics and meteorological data from KEY-90. Naval Command, Control and Ocean Surveillance Center, San Diego, CA, USA, Technical Report 1608 (September 1993).

58. De Leeuw, G. (1991). Aerosol models for optical and IR propagation in the marine atmospheric boundary layer. Propagation Engineering: Fourth in a series, L.R. Bissonnette and W.B. Miller (Eds.), Proc. SPIE 1487, 130159.

59. De Leeuw, G., K.L. Davidson, S.G. Gathman, R V. Noonkester (1989a). Modeling of Aerosols in the Marine Mixed-Layer. In: Propagation Engineering, SPIE proceedings, vol 1115, , p 287-294.

60. De Leeuw, G., K.L. Davidson, S.G. Gathman and R. V. Noonkester (1989b). Physical Models for Aerosol in the Marine Mixed-Layer. In: Operational decision aids for exploiting or mitigating electromagnetic propagation effects, AGARD-CP 453, pp. 40-1 to 40-8.

61.Davidson, K.L., G. de Leeuw, S.G. Gathman and D.R. Jensen (1990). Verification of the Naval Oceanic Vertical Aerosol Model During FIRE. In: FIRE Science Results 1989, D.S. McDougal, editor, NASA Conference Report \#3079, pp. 191-196.

62. Gerber, H., S.G. Gathman, J. James, M.H. Smith, I. Consterdine and S. Brandeki (1990). NRL Tethered Balloon Measurements at San Nicolas Island during FIRE IFO 1987. In: FIRE Science Results 1988, D.S. McDougal and H.S. Wagner, editors, NASA conference publication \#3079, 191-196.

63. Cecere, T.H. (1991). An Evaluation of the Naval Oceanic Vertical Aerosol Model during Key-90. Thesis. Naval Postgraduate School, Monterey, CA, USA.

64. De Leeuw, G. and G.J. Kunz (1992). NOVAM Evaluation from Aerosol and Lidar Measurements in a Tropical Marine Environment, In: Atmospheric Propagation and Remote Sensing, A. Kohnle and W.B. Miller (Eds.), Proc. SPIE 1688, 14-27.

65. Paulson, M.R, and H.G. Hughes (1990). A lidar technique for adjusting aerosol model number densities close to the ocean surface. Naval Ocean Systems Center Technical Report 1388, December 1990.

66. De Leeuw, G. (1993b). Aerosols near the air-sea interface. Trends in Geophys. Res. 2, 55-70.

67. Van Eijk, A.M.J., and G. de Leeuw (1992). Modeling aerosol particle size distributions over the North Sea. J. Geophys. Res. 97, (Vol. C9), 14417-14429.

68. Monin, A.S., and A.M. Obhukov (1954). Basic turbulent mixing laws in the atmospheric surface layer, Trudy, Geofys. Inst. AN SSSR, No 24 (151), 163-187.

69. Liu, W.T., K.B. Katsaros, and J.A. Businger (1979). Bulk Parameterizations of Air-Sea Exchanges of Heat and Water Vapor Including the Molecular Constraints at the Interface. J. Atm. Sci. 36, 1722-1735.

70. Jensen, D.R, R. Jeck, G. Trusty and G. Schacher (1983). Intercomparison of Particle Measuring Systems, Inc's particle-size spectrometers. Opt. Eng. 22, 746-752.

71. Jensen, D.R. (1995). EOPACE workplan. NRaD, San Diego, USA

72. Hurtaud, Y. (1996). Private communication.

73. De Leeuw, G. (1990). Profiling of aerosol concentrations, particle size distributions and relative humidity in the atmospheric surface layer over the North Sea. Tellus 42B, 342-354, 1990. 
Technical Document 2938

December 1996

\title{
Proceedings of the 1996 Battlespace Atmospherics Conference 3-5 December 1996
}

\author{
Editors: J. H. Richter K. D. Anderson
}

Naval Command, Control and Ocean Surveillance Center RDT\&E Division

San Diego, CA 92152-5001 